\title{
Kinematic Storage Model (KSM) for Groundwater Development in Highly Permeable Hill Slope-Laboratory Study
}

\author{
Dak Bahadur Khadka \\ Lecturer, Eastern Regional Campus, Civil Engineering Department Institute of Engineering, Tribhuvan University, \\ Kathmandu, Nepal \\ Email: dakkhadka@ioepc.edu.np
}

How to cite this paper: Khadka, D.B. (2019) Kinematic Storage Model (KSM) for Groundwater Development in Highly Permeable Hill Slope-Laboratory Study. Open Journal of Civil Engineering, 9, 195-210. https://doi.org/10.4236/ojce.209.93014

Received: June 24, 2019

Accepted: July 28, 2019

Published: July 31, 2019

Copyright (c) 2019 by author(s) and Scientific Research Publishing Inc. This work is licensed under the Creative Commons Attribution International License (CC BY 4.0).

http://creativecommons.org/licenses/by/4.0/

\begin{abstract}
Study of the groundwater table development and runoff generation is one of the most important parts of hydrology to develop a clear concept, especially in hill slope. The study is more complex in the real field rather than in the artificial system. The result in artificial systems developed and experimental observations may give good results. So, therefore, this study is aimed at modeling in the laboratory as artificial hill slope flows which include saturation excess surface runoff flows. The physical processes along with runoff generation depend on the factors-soil type, characteristic slope geometry, and initial soil conditions at the commencement of rainfall. The mechanisms involved in runoff formation process have been simulated successfully to compute hydrograph for hilly terrain and groundwater table development in highly permeable soil tested by kinematic storage model theory. The model represents the hill slope as a rectangular storage element of length $2.02 \mathrm{~m}$, depth $0.15 \mathrm{~m}$ and width $1 \mathrm{~m}$ With an impermeable bed making an angle of 10 degrees with the horizontal. The storage element is composed of two moisture zones: an unsaturated zone and a saturated zone. The result obtained is seemed good adjustment to the theory of hill slope model given by $\mathrm{Nm}$ Shakya, 1995. Aslo, the moisture profile variation in mixed sand profile was found immediately after the rainfall event. The result obtained shows that the timing and distribution of moisture over the depth where the maximum moisture content is 0.4 in mid of the depth which is more than in surface having a moisture level of 0.37 .
\end{abstract}

\section{Keywords}

Hill Slope, Subsurface Flow, Ground Water Table, KSM Theory, Moisture Profile 


\section{Introduction}

Hill slope stability is an important state of hill to avoid the land slide due to intense rainfall. In infinite slope length with highly permeable soil has high infiltration rate having the maximum volumetric capacity to store the infiltrated water. In such cases, the saturated conductivity of soil is always greater than the rainfall rate so therefore the rainfall water infiltrates into soil completely. If the depth of soil is low then the saturation level increases toward the slope surface and a time comes to reach the surface to be saturated and overland flow occurs. Hill slope having infinite length, the infiltrated water has high active pressure so that it may cause the land slide from a weak crack or fault line or the fault may be developed due to high shear stress development [1]. The initial moisture condition has significant role in the rise in moisture level and time for saturation. High antecedent moisture level causes fast surface saturation resulting starts of surface runoff as soon. Before the start of surface runoff, the subsurface flow is prominent to contribute the discharge in the river at the end of hill slope, the rate of which can be given by Darcy equation as:

$$
Q=K I A
$$

where $K$ is the hydraulic conductivity of soil in $\mathrm{cm} / \mathrm{se}, I$ is the hydraulic gradient (slope of the water pore pressure) and $A$ is the section area of the slope.

The seepage flow through subsurface is laminar in nature but may cause piping action from the ground level and may lead to the land slide [2]. The groundwater table depends on soil slope and type of soil. The moisture profile and its time for saturation completely depend on the rainfall intensity and its duration. Green and Ampt model gives the total volume infiltration and it's time for saturation. Which depends on the initial moisture deficit (IMD), the average hydraulic potential of soil, rainfall intensity and hydraulic conductivity. After the soil saturation, further rainfall cause rise in infiltrated volume due to the hydraulic conductivity which is less than the saturation conductivity. The rapid rise in moisture level causes the surface runoff earlier in the hill [3]. The infiltration rate can be estimated in ideal natural soil by different models among which the Hortan's equation (1930s) is more accurate. The rise in moisture with depth depends on the particles size distributions and pore size i.e. micro pore and macro pore interconnections of soil particles and it affects the capillary sanction and potential in soil [1]. The flow is in steady-state condition that follows to the kinematic wave approximation theory with Darcy law and the cause of flow is pore water pressure and gravitational force and the flow can be modeled by dynamic wave approximation theory too [4]. The interconnection of hill slope and river is the main source of water in the river due to subsurface flow and it may be three-dimensional or may be one-dimensional flow that can be analyzed by three-dimensional dynamic equation or assuming one-dimensional kinematic wave equation [5].

The moisture variation in hill slope and estimation of surface runoff is a challenging issue in hilly areas in case of under developed country as the massive 
road construction work going on has made the natural hill slope profile disturbed due to heavy load excavator operation for cut and fill. The deforestation effect has been experienced to depletion of small water sources like pond, lake, and strings which are sources of drinking water in hilly areas. It has become a serious problem and people are forced even to migrate searching for the area where water is sufficiently available [6]. The vegetation, type of crop and land use pattern, is also a important factor affecting the infiltration process especially in clayey type soil slope which reduces to the surface runoff and enhances groundwater recharge [7]. So the study of the subsurface flow and its direction is felt to be carried out in an easy way which gives reliable results. Also, the aim of the study is to give validation for the existing water development process in hill slope despite the length of the slope but on the basis of initial moisture condition, the soil type and its slope. The study in real natural hill slope is a difficult process and the estimation of pore water will not be accurate. To give a clear concept of underground water development the laboratory approach is seemed mostly used even in literature. So for the study, a rainfall simulator is used in which an artificial rainfall of very low to intense rainfall can be made of short as well as long duration over the artificial catchment prepared at a certain slope. As the simulator is portable the slope angle can be made of the desired value. As set up is modeled a hill slope at an angle of $10^{\circ}$ with the horizontal, the physical process occurred within the catchment represents the rainfall runoff process occurred in real hill terrain. The concept of underground water table, its hydrographs and the moisture profiles may represent or reflects the processes occurs in the real terrain.

\subsection{Objectives of the Study}

The study aims the following objectives

- To carry out the low and intense artificial rainfall drop over the artificial catchment to observe its rainfall and runoff process in highly permeable sand slope.

- To observe the rise in pore water pressure along the length of hill slope so that the hydraulic grade line can be marked.

- The development of the rise in moisture level which represents the water table development process in highly permeable soil and the time for saturation at which the surface runoff starts. The moisture profile immediate after a rainfall event can be observed at different time interval. And to validate, the groundwater development process in sandy soil by kinematic storage model (KSM).

\subsection{Governing Equations}

\section{Infiltration in the Ideal \& Natural Soil}

Infiltration is one of the most important factors in hydrology which influences to the groundwater and its estimation is complex [8]. The ideal soil is considered 
to be one which is homogeneous throughout the profile, and in which all of the pores are interconnected by capillaries. In addition, it is assumed that the applied rainfall falls uniformly over the soil surface. Because the movement of water into the soil is really uniform, the infiltration process can be considered to be one dimensional. For this ideal case, perhaps the most important factors, which affect the infiltration capacity, are soil type and moisture content. The soil type determines the size and number of the capillaries through which the water must flow. The moisture content determines the capillary potential in the soil and the relative conductivity as shown for a typical soil in Figure 1. For low moisture content, the suctions are high and the conductivity low. At high moisture contents, near saturation, the soil suction is low, and the relative conductivity is high. One can now examine a typical infiltration event-rainfall falling on a dry soil. Because the initial moisture content is low the relative conductivity is small. This implies that the moisture level must be higher before water will move further into the soil mass. Because of this, a distinct wetting front will form with the moisture content ahead of the front still low, and the soil behind the front virtually saturated. A considerable capillary suction exists at the wetting front. In case of highly permeable soil having sufficient depth if the rainfall rate is lower than the infiltration rate or field capacity of soil the infiltrated volume will be greater than at the saturation condition in shallow depth. And for this soil slope, the rise in water table due to a long duration rainfall can be estimated by the well-known equation kinematic storage Model in hill slope [1]. The rainfall intensity its duration is the most important for the moisture storage in hill slope [9]. The infiltration curve goes exponentially in dry soil always [10] as shown in Figure 1. Also, Figure 2 is the hypothetical moisture profile during rainfall event in soil. Figure 3 is the corresponding infiltration curve of Figure 2 during the rainfall event.

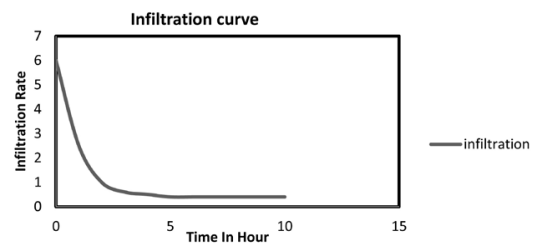

Figure 1. Section of infiltration with time.

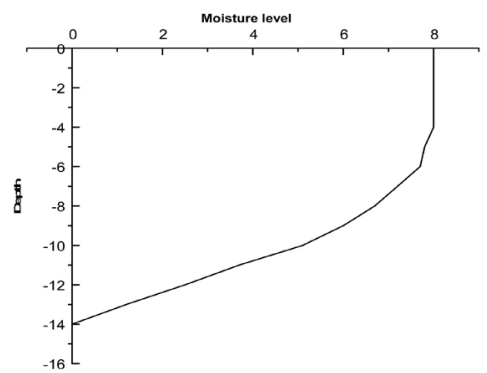

Figure 2. Section of Hypothetical moisture profile with depth due to rainfall event at saturated condition. 


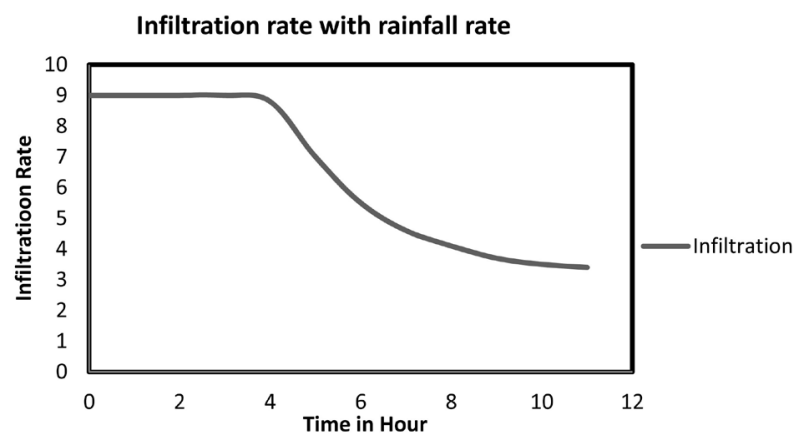

Figure 3. Section of infiltration due to different rainfall rate with time period.

\subsection{Kinematic Storage Model}

The moisture storage depends on the soil type, its slope and hill slope geometry [11]. It also depends on the rainfall duration and the time interval. It varies for long time interval record and immediate after the rainfall occurs at shallow and deep soil [12]. There are various analytical models for soil moisture study in both saturated and unsaturated conditions. kinematic wave equation and Hill slope storage Boussinecsq based on darcy law are mostly used model [13]. The hill slope model as shown in Figure 4 represents the hill slope as a rectangular storage element of length $L 2.0 \mathrm{~m}$ and depth $D 0.15 \mathrm{~m}$ and width $1 \mathrm{~m}$, making an angle of $\alpha$ (10 degree) with the horizontal. The continuity equation for the saturated zone may be expressed as:

$$
\frac{\mathrm{d} \theta_{u}}{\mathrm{~d} t}=L(r-i)
$$

Or in finite difference form

$$
\frac{\theta_{u 2}-\theta_{u 1}}{\Delta t}=L(r-i)
$$

where $\theta_{u}$ is the average volumetric water content in the unsaturated zone, $r$ is the precipitation input rate, $i$ is the vertical input rate to the saturated zone subscript 1 and 2 represents refer to the beginning and end of the time step, respectively. Sloan and Moore (1984) assumed that the vertical input rate is a function of the volumetric water content, i.e.

$$
\begin{gathered}
i=K\left(\theta_{u}\right) \\
i=\frac{K_{s}\left(\theta_{i}-\theta_{r}\right)}{\theta_{s}-\theta_{r}} \\
\theta_{u 2}=\frac{\theta_{u 1}+L(R-i) \Delta t}{\text { Vunsat }}
\end{gathered}
$$

where $k$ is hydraulic conductivity.

The continuity equation for the saturated storage element may be expressed as:

$$
\frac{\mathrm{d} S}{\mathrm{~d} t}=i L-q
$$




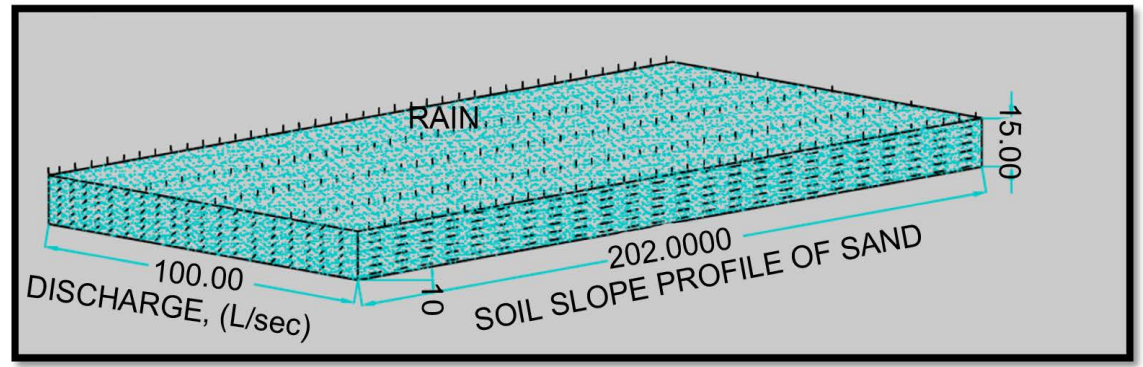

Figure 4. The 3-D profile of hill slope geometry.

Or in finite difference form

$$
\frac{S_{2}-S_{1}}{\Delta t}=i L-\frac{q_{1}+q_{2}}{2}
$$

where $S$ is the drainable water stored in the saturated zone per unit with and $q$ is the discharge from the profile per unit width.

$$
\begin{gathered}
S=\frac{\operatorname{Lh} \theta_{\text {drain }}}{2} \\
\theta_{\text {drain }}=\theta_{s}-\theta_{r}
\end{gathered}
$$

where $h$ is the depth of the water table at the outlet and $\theta_{\text {drain }}$ is the drainable porosity of the soil. With the assumption that the hydraulic gradient is equal to the bed slope, the discharge per unit width at the outlet is given by Darcy's law as:

$$
q=V h
$$

where $\mathrm{v}$ is the velocity of flow at the out let and is given by

$$
V=K_{s} \sin \alpha
$$

where $K_{s}$ is the saturated hydraulic conductivity and $\alpha$ is the hill slope angle. The water table outlet depth at the end of any time interval $\Delta t$ may be determined explicitly by:

$$
h_{2}=h_{1} \frac{\left(L \frac{\theta_{\text {drain }}}{\Delta t}-V\right)+2 i L}{\frac{L \theta_{\text {drain }}}{\Delta t}+V}
$$

\section{Method of Study and Material}

The rainfall simulator (Rig) product of Arm field company UK (Figure 5) has been used for the study having the capacity to generate rainfall event of small to intensive intensity of constant vertical drop size distributed in time and space over the catchment prepared. The setup is useful for the experimental study on sub-surface and surface flow due to a rainfall event. Also, the simulator has a good capacity to study the groundwater table development and effects on hydraulic gradient due to infiltration of water from the soil to the groundwater. The setup is so made that the change in water pressure can be observed on the 
Setup preparation of the rain fall simulator
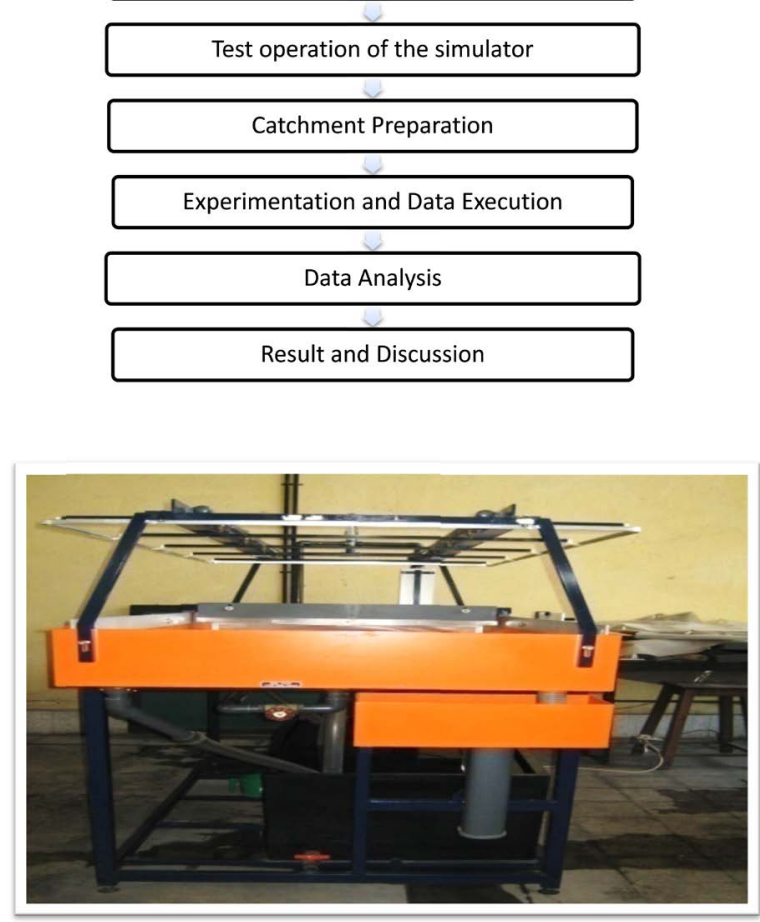

Figure 5. Photos rainfall simulator catchment tank (S12-Basic Hydrology system S12)

manometers attached to Figure 6. The rise in water in the piezometers (manometers) indicates the rate of water table development in the soil slope constructed which can be studied by the theoretical equations available on the hill slope runoff process. Also, the setup provides a comparative evaluation of runoff generation, hydrograph, and rainfall-runoff correlation graphs peak discharge-time of concentration Nomograms, underground water table development and time parameters under controlled conditions. The good abstraction and effects on influence radius can be studied from the set up The simulator has the main components as in Figure 7 having the size of the catchment tank of length $2.02 \mathrm{~m}$, width $1 \mathrm{~m}$ and depth $0.15 \mathrm{~m}$ in which the material as prescribed by Figure 8 is to be filled making the desired slope to the profile constructed. This item is a completely self-contained unit and requires only laboratory electrical connections. The electrical sump is to be operated for the rainfall which requires the power of 220 volts, $50 \mathrm{HZ}$. Regular special care and maintenance are necessary to keep the set in good conditions [14]. This experimental study follows the following flow chart as shown:

\section{Setup Preparation}

Before the catchment preparation the rig should be checked cautiously and the each component must be in well function conditions for this the following should be carried out.

1) Check that the pump motor electrical specification complies with the mains supply. 


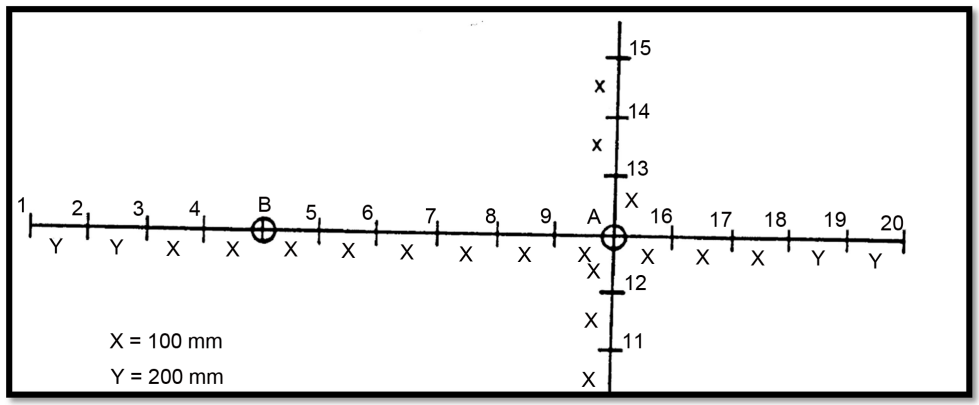

Figure 6. Taping points of manometers of the simulator for water pressure measurements.

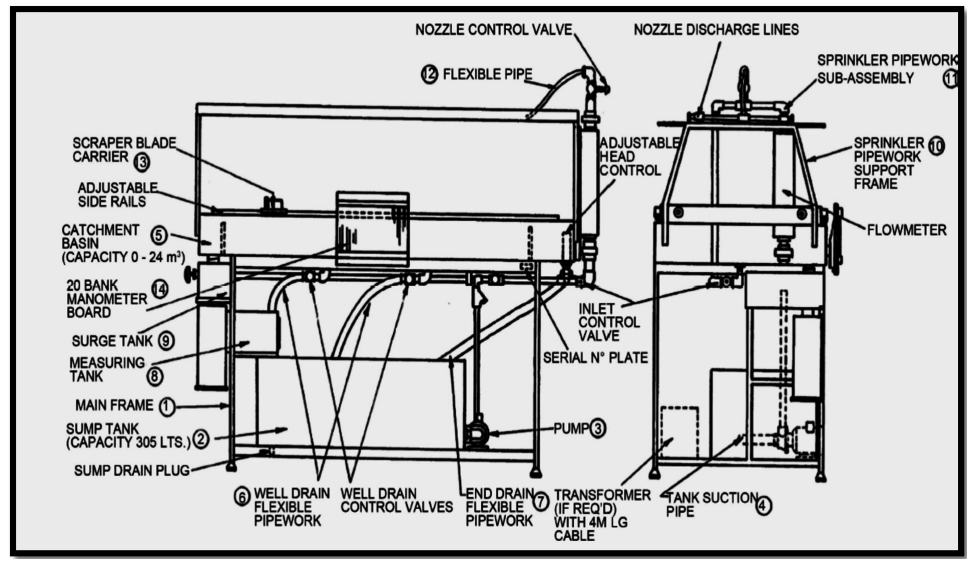

Figure 7. Components of the simulator-S12, (Source-Instruction Manual, Armfield Company, UK).

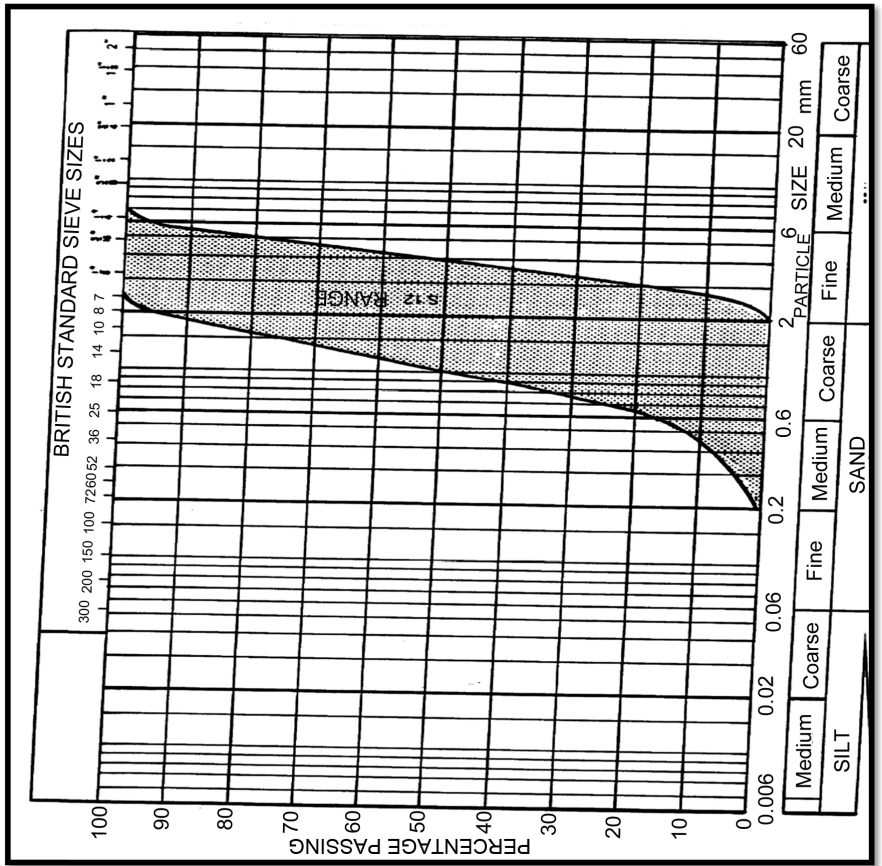

Figure 8. Sand size grading curve for simulator-S12 (Source-Instruction manual, Armfield Company, UK). 
2) Adjust both side rails to "maximum" slope, set the scraper blade to the "lowest" setting and check that the blade clears the two well drains while the carriage traverses the length of the catchment basin.

3) Fill the sump tank, close all valves, switch on the pump and check correct pump rotation.

4) Open both inlet control valves to fill catchment basin and check for leaks.

5) Open well drain control valves and check for leaks.

6) Open sprinkler control valve and ensure that all sprinklers are operating correctly. Check for leaks.

7) Adjust inlet control valves and check function of flow meter.

8) Allow water into the measuring channel and confirm that the flow calibration is identical with that of the flow meter indicator over the full angle.

9) Close all valves. Fill the catchment basin with $25 \mathrm{~mm}$ depth of water to expel air from the manometer tubes, manipulating tubes to assist this operation, if required. The equipment is now ready to be filled with sand for experimental purposes.

\section{Grading Size of Material for the Simulator}

The size and grading of the sand used in the catchment tank can be chosen to meet the particular needs of the experimenter. Fine sand will normally give a lower coefficient of permeability, and hence slower run-off and steeper water table slopes, than a coarse one. Similar results will be found if a well-graded sand (one in which a range of sizes is present in approximately (qual parts) is used compared with a single size fraction. It is most important that any sand used should be first thoroughly washed to remove all silt and salt present. Figure 8 shows the recommended range of sizes and grades to cover all experiments where comparative results are required. The best size for the run-off experiments is in the range of $2-5 \mathrm{~mm}$. While, for studying the water table draw-down and well abstraction, a slightly smaller size is desirable, say $0.2-2 \mathrm{~mm}$. It would, therefore, seem sensible to obtain sand as close to $2 \mathrm{~mm}$ as is possible if the full range of experiments is to be explored.

The material used for the simulator should be of $0.2 \mathrm{~mm}$ to $2 \mathrm{~mm}$ size for this study. The fine and mixed sand can be used for the test material forming the catchment area. The chart in Figure 8 shows the particle size for simulator S12 [15].

\section{Catchment Preparations}

As per the material required was collected by sieving the sand in the mixed form of 0.2 to $2 \mathrm{~mm}$ and was collected in the tank to construct the catchment. It was filled as per the specification of the instruction manual and marked line within the tank of total area $0.202 \mathrm{~m}^{2}$ and volume of $0.24 \mathrm{~m}^{3}$. The slope was made at 10 degree with the horizontal plane. After the reconnaissance, detailed leveling was done by trial and error method so that accuracy was maintained. As all facilities for controlling, collecting, and runoff reading facilities are already associated became easier to observe, collect and measure runoff. Time observa- 
tion was done by stopwatch provided. After the completion of the profile preparation, the test was carried out and data recording were done simultaneously. As our main aim was to observe the instantaneous runoff discharge, time of concentration and peak discharge due to the different rainfall intensities from 3 $1 / \mathrm{min}$ to $13 \mathrm{l} / \mathrm{min}$ was recorded. The manometer readings were observed at the one-minute intervals with the help of stopwatch which showed the rise of sub-surface water table in soil. Figure 9 below is the constructed soil slope profile within the rig.

\section{Results and Discussion (Model Performance)}

The catchment prepared represented the hill slope as a rectangular storage element of Length $2.02 \mathrm{~m}$ and Depth of $0.15 \mathrm{~m}$ (Figure 4 Micro topography) with impermeable bed making an angle $\alpha$ (10 degree) with the horizontal plane. The soil is comprised of unsaturated with initial moisture content of 0.23 and saturated moisture content of 0.45 . The residual moisture content for sand lays $5 \%$ $10 \%$. So $10 \%$ was taken for the prediction at the uniform rainfall intensity of 0.25 $\mathrm{cm} /$ minute. Permeability of the soil is assumed as $0.3 \mathrm{~cm} / \mathrm{min}$ During the rainfall, kinematic wave approximation was used for the prediction of the possible velocity. The depth estimation and observation were done at the time of one-minute interval. From the observation after 15-minute rainfall at the rate of $5 \mathrm{ltr} / \mathrm{min}$, the manometer reading was stable at $127 \mathrm{~mm}$. Which indicated the subsurface flow was up to 15 minutes and afterwards overland flow started. Up to that time period, the discharge was observed $0.1125 \mathrm{ltr} / \mathrm{se}$ while from the kinematic storage model it was predicted $0.15 \mathrm{ltr} / \mathrm{se}$. Immediate after that rainfall was stopped and the recession value was observed at the one minute time intervals and made comparison with the predicted from kinematic storage model theory. As Figure 10 shows the rainfall runoff simulation and rise in pore water pressure in manometers attached with the simulator

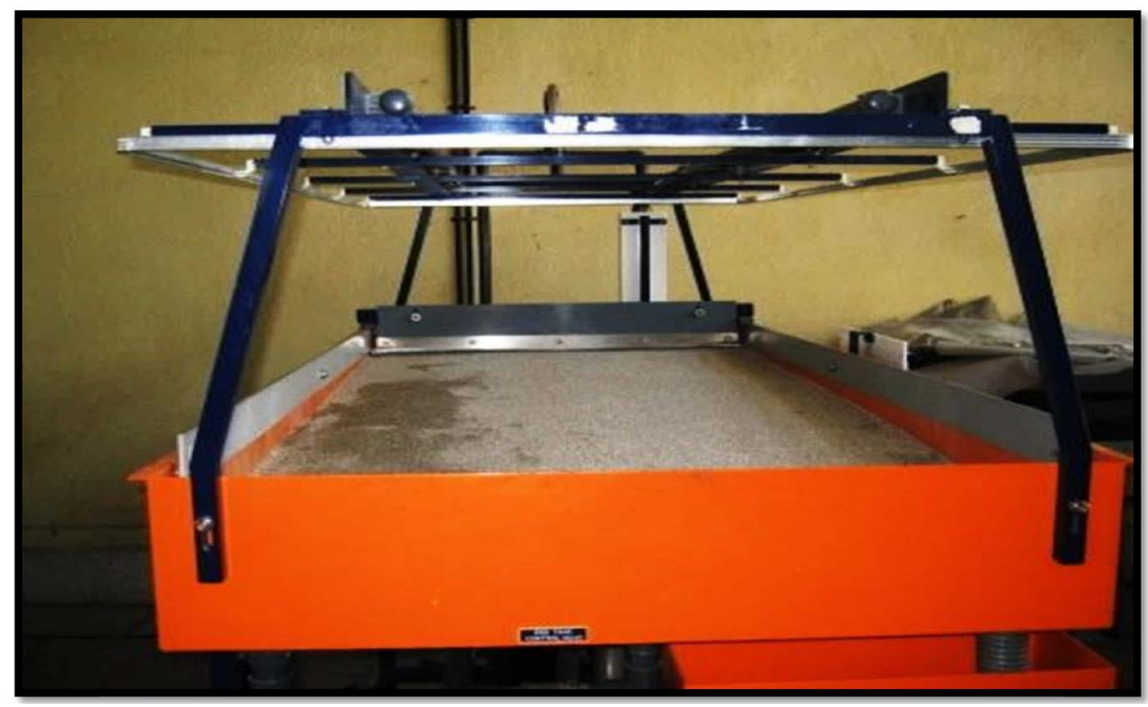

Figure 9. Photos (simulated Rainfall-Runoff test on sand plot). 
As the initial moisture content of the sand was $23 \%$, the change in the moisture content during the rainfall was primary analysis as it contributed to the infiltration rate of the water into the bottom layer of the soil (Figure 11). So the moisture profile from the kinematic storage model was obtained as in Table 1 and Figure 12 for light rainfall period and after rainfall stopped. From the result, it seemed clear raise in the moisture content on the sand maximum of $39 \%$ which was near about the saturation moisture content tested and was an acceptable value. After rain, the moisture profile was reverse of rainfall period. This validated the general principle of the moisture content phenomena in sandy soil due to rainfall.

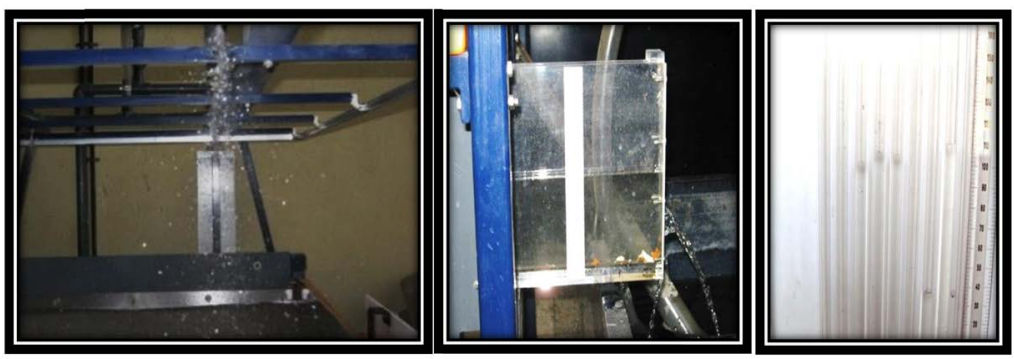

Figure 10. Photos of the rainfall events made, outlet discharges and soil water pressure heads.

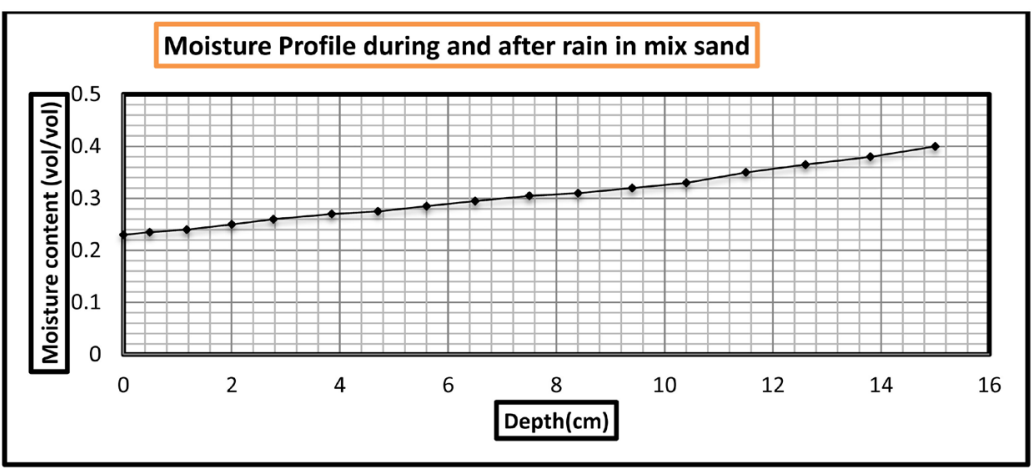

Figure 11. Moisture profile with depth in sand profile.

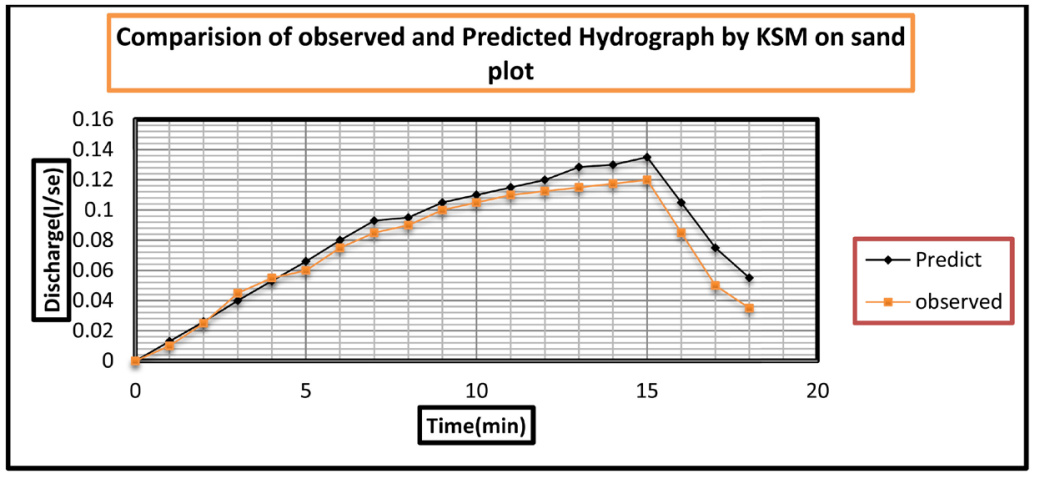

Figure 12. Comparison of runoff between predicted kinematic theory and observed hydrographs. 
Table 1. The kinematic storage model analysis and observed data recorded.

\begin{tabular}{|c|c|c|c|c|c|c|c|}
\hline $\begin{array}{c}R \\
(\mathrm{~cm} / \mathrm{hr})\end{array}$ & $\begin{array}{l}\text { Time } \\
(\mathrm{min})\end{array}$ & $\begin{array}{l}\text { Moisture } \\
\quad\left(\theta_{u}\right)\end{array}$ & $\begin{array}{c}i \\
(\mathrm{~cm} / \mathrm{min})\end{array}$ & $\begin{array}{c}K_{s} \\
(\mathrm{~cm} / \mathrm{min})\end{array}$ & $\begin{array}{c}V_{s}= \\
K_{s} \sin \alpha\end{array}$ & $\begin{array}{c}\text { Estimate } \\
H(\mathrm{~cm})\end{array}$ & $\begin{array}{c}\text { Observed } \\
H(\mathrm{~cm})\end{array}$ \\
\hline 15 & 0 & 0.23 & 0 & 0.3 & 0.052 & 0 & 0 \\
\hline 15 & 1 & 0.24 & 0.085 & 0.3 & 0.052 & 0.485 & 0.5 \\
\hline 15 & 2 & 0.25 & 0.12 & 0.3 & 0.052 & 1.169 & 1.25 \\
\hline 15 & 3 & 0.259 & 0.137 & 0.3 & 0.052 & 2 & 1.75 \\
\hline 15 & 4 & 0.269 & 0.145 & 0.3 & 0.052 & 2.77 & 2.5 \\
\hline 15 & 5 & 0.28 & 0.153 & 0.3 & 0.052 & 3.85 & 3.5 \\
\hline 15 & 6 & 0.29 & 0.162 & 0.3 & 0.052 & 4.7 & 4.25 \\
\hline 15 & 7 & 0.3 & 0.17 & 0.3 & 0.052 & 5.6 & 5.5 \\
\hline 15 & 8 & 0.31 & 0.18 & 0.3 & 0.052 & 6.5 & 6.25 \\
\hline 15 & 9 & 0.32 & 0.19 & 0.3 & 0.052 & 7.5 & 6.75 \\
\hline 15 & 10 & 0.33 & 0.205 & 0.3 & 0.052 & 8.4 & 8.25 \\
\hline 15 & 11 & 0.34 & 0.21 & 0.3 & 0.052 & 9.4 & 8.75 \\
\hline 15 & 12 & 0.35 & 0.215 & 0.3 & 0.052 & 10.4 & 9.5 \\
\hline 15 & 13 & 0.36 & 0.225 & 0.3 & 0.052 & 11.5 & 10.75 \\
\hline 15 & 14 & 0.37 & 0.234 & 0.3 & 0.052 & 12.6 & 11.25 \\
\hline 15 & 15 & 0.38 & 0.24 & 0.3 & 0.052 & 13.8 & 12 \\
\hline 15 & 16 & 0.39 & 0.245 & 0.3 & 0.052 & 15 & 12.7 \\
\hline
\end{tabular}

\subsection{Runoff Volume}

From the comparative analysis, it seemed the total drainage volume of the water from the catchment of mixed sand was 72 liter whereas the kinematic storage model showed its value of 78.26 liters. But the rainfall rate was of $5 \mathrm{l} \mathrm{pm}$, rainfall period of 15 minutes. So the total rainfall volume was 75 liters. However, the rained water was more than 75 liter because even after switching off the sump motor it had drawn water already so there was rain after the stop of the motor run and rainfall stop took time a bit more. Figure 13 was the result obtained. Hence, from the analysis, the variation of the prediction and observation is not so unrealistic and the experimentation conducted seemed under the KSM theory and obeyed it in terms of volume.

\subsection{Runoff Hydrograph}

After saturation of the soil, the overland flow started at a rainfall rate of $5 \mathrm{lpm}$ and runoff at lps was recorded at the time interval of one minute with the help of stop watch. At the time of concentration (Tc) of 18 minutes, the peak discharge $0.13 \mathrm{lps}$ were recorded. Then after the rainfall was stopped and recession was recorded. Figure 14 below shows the hydrograph obtained on the sand plot soil slope. At the peak discharge, the runoff coefficient was obtained within the range 


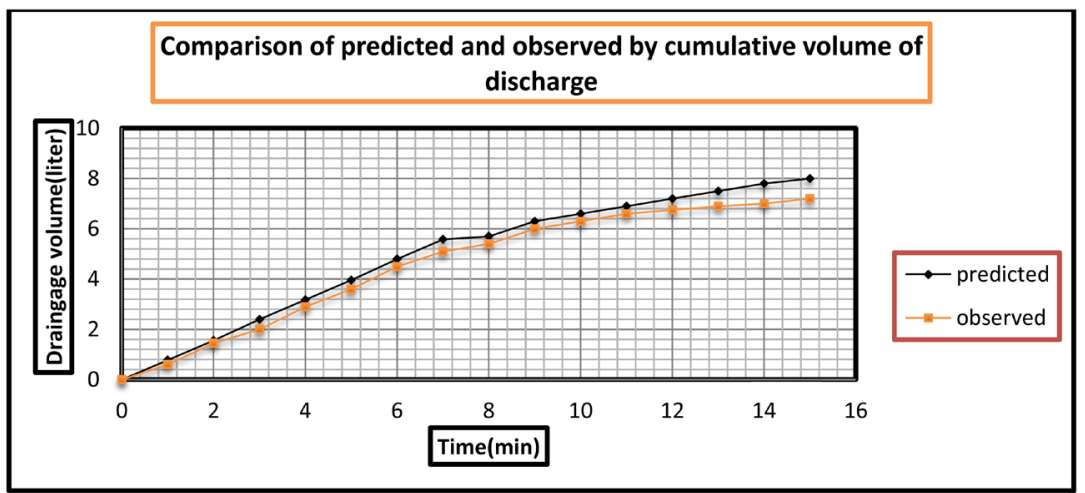

Figure 13. Comparison between observed and predicted runoff volume curves for sand plot.

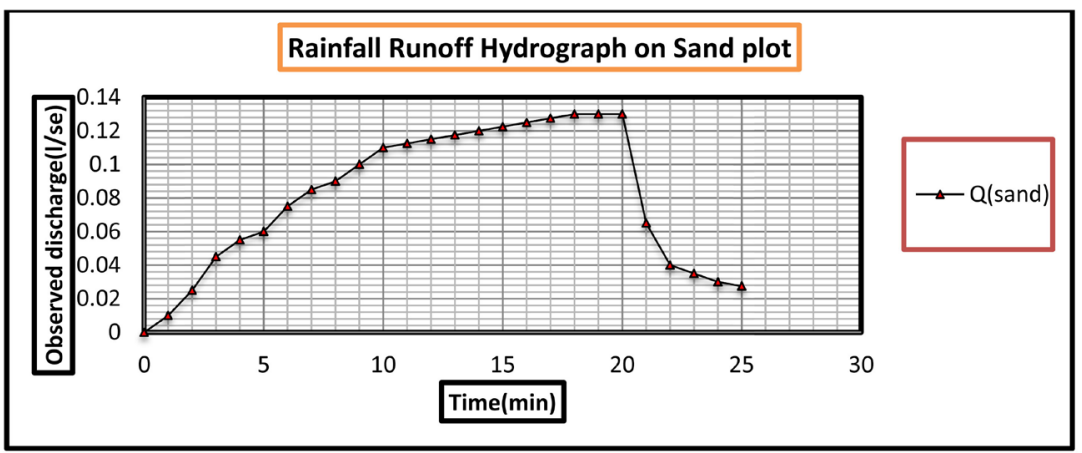

Figure 14. Runoff hydrograph on sand slope after saturation.

of 0.4 to 0.52 by rational method for the catchment which is within the standard value as 0.05 to 0.9 . Figure 15 shows the variation of runoff coefficients for the slope profile at different rainfall rate according to the rational formula for small catchment producing surface runoff after saturation.

\subsection{Moisture Profiles}

The comparison of moisture profile for sand of sizes $0.2 \mathrm{~mm}$, and $2 \mathrm{~mm}$ (mix and fine), over the depth was found as shown in Figure 16. It was observed under the intense rainfall rate of $15 \mathrm{lpm}$ for 5 minute at which the overland flow occurred. Since the infiltration capacity of the fine and mixed sand was high due to the larger size macrospores, significant moisture transaction took place within the pores resulting in the complete adjustment of the moisture. The percolating rate in the larger size of the pore was high so the high moisture content was measured at the mid of the mixed sand. The moisture contents were measured just after the rain in soil slopes. Owing to the low depth, the moisture profiles obtained are not exactly alike as found in the hill slope scale runoff process as explained by Shakya (1995) and S, Scheres (1996). However; the result obtained shows that the timing and distribution of moisture over the depth are a good agreement with that produced by Shakya (1995) and Scherer (1996) for immediate after rainfall occurs in hill slope. 


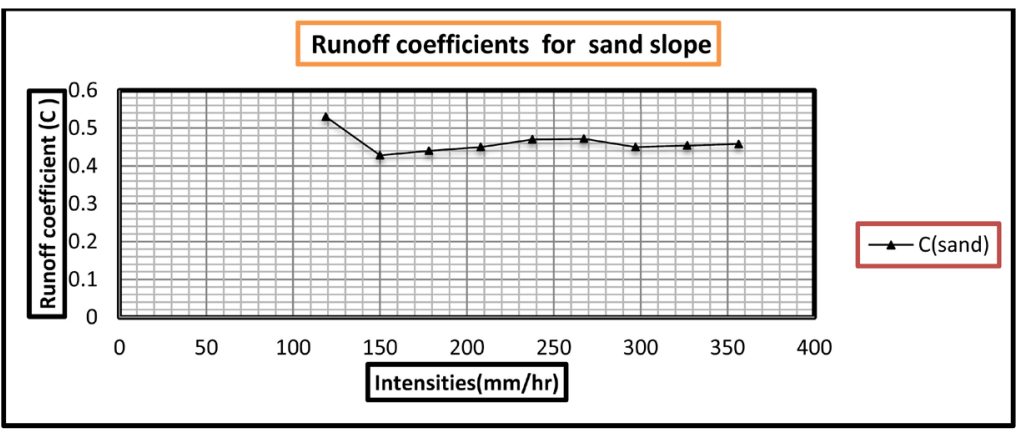

Figure 15. Variation of runoff coefficient with the rainfall rate in sand soil slope.

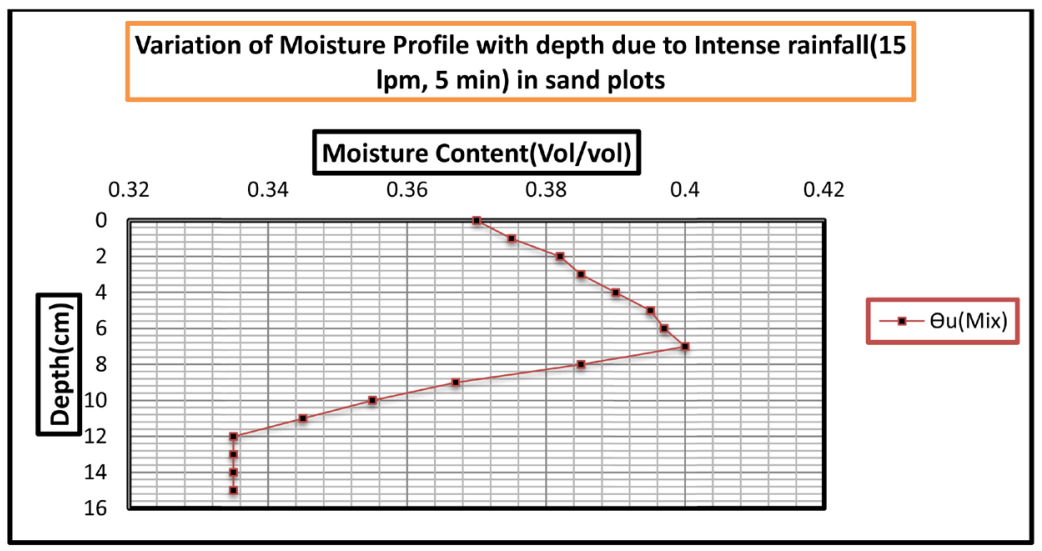

Figure 16. Moisture profile with depth due to intense rainfall in sandy soil immediate after rainfall event.

\section{Conclusions}

$\checkmark$ Validation by the Hill Slope runoff Process with Kinematic Storage Model to the observation for the sand slope has been ascertained that the experiments obeyed the theory of hill slope model and applicability of the KSM theory for the hill slope runoff analysis with permeable soil. It is observed a realistic result between the observed and predicted values which also shows a good adjustment between KSM theory and physical hill slope runoff process. The peak values for the estimated was found $15 \mathrm{~cm}$ whereas observed value was $12.7 \mathrm{~cm}$. The total infiltrated volume was 78.26 liters by the model estimation whereas the rainfall gave was of 75 liter which is considerable values as there is a small variation between estimated and observed.

$\checkmark$ Owing to the low depth, the moisture profiles obtained are not exactly alike as found in the hill slope scale runoff process as explained by Shakya (1995) and S. Scheres (1996). However; the result obtained shows that the timing and distribution of moisture over the depth are good agreement with that produced by Shakya (1995) and Scherer 1996.

$\checkmark$ The moisture variation should be observed on the other soil slopes like clay and silt so that the moisture variation can be observed and a comparison can be made under different time interval of rainfall events occurred. 


\section{Acknowledgements}

I am extremely grateful to the publication open journal of Civil Engineering and My Campus Eastern Region campus Dharan, IOE TU.

\section{Conflicts of Interest}

The authors declare no conflicts of interest regarding the publication of this paper.

\section{References}

[1] Shakya, N.M. and Chander, S. (1998) Modelling of Hillslope Runoff Processes. https://doi.org/10.1007/s002540050298

[2] Talebi, A., Uijlenhoet, R. and Troch, P.A. (2007) Soil Moisture Storage and Hillslope Stability. Natural Hazards and Earth System Sciences, 7, 523-534. https://doi.org/10.5194/nhess-7-523-2007

[3] Hossain, M.M. and Ema, J.F. (2013) Solution of Kinematic Wave Equation Using Finite Difference Method and Finite Element Method. Double Blind Peer Reviewed International Research Journal, 13.

[4] Rezzoug, A., Schumann, A., Chifflard, P. and Zepp, H. (2005) Field Measurement of Soil Moisture Dynamics and Numerical Simulation Using the Kinematic Wave Approximation. Advances in Water Resources, 28, 917-926. https://doi.org/10.1016/j.advwatres.2005.02.010

[5] Troch, P., van Loon, E. and Hilberts, A. (2002) Analytical Solutions to a HillslopeStorage Kinematic Wave Equation for Subsurface Flow. Advances in Water Resources, 25, 637-649. https://doi.org/10.1016/S0309-1708(02)00017-9

[6] Dhakal, S. (2013) Flood Hazard in Nepal and New Approach of Risk Reduction. International Journal of Landslide and Environment, 1, 13-14.

[7] Chapman, T.G. (2005) Recharge-Induced Groundwater Flow over a Plane Sloping Bed: Solutions for Steady and Transient Flow Using Physical and Numerical Models. Water Resources Research, 41, 1-12. https://doi.org/10.1029/2004WR003606

[8] Kadam, A.S. (2016) Determination of Infiltration Rate for Site Selection of Artificial Water Recharge: An Experimental Study. International Journal of Science and Research, 5, 6-391.

[9] Li, X.Y., Contreras, S., Solé-Benet, A., Cantón, Y., Domingo, F., Lázaro, R., et al. (2011) Controls of Infiltration-Runoff Processes in Mediterranean Karst Rangelands in SE Spain. CATENA, 86, 98-109. https://doi.org/10.1016/j.catena.2011.03.003

[10] CE ITT, Kharagpur (2005) The Science of Surface and Ground Water Lesson: Module 2. CE IIT, Kharagpur.

[11] Water Resources Research (2018) Effects of Unsaturated Flow on Hillslope Recession Characteristics.

[12] Yang, L., Wei, W., Chen, L., Jia, F. and Mo, B. (2012) Spatial Variations of Shallow and Deep Soil Moisture in the Semi-Arid Loess Plateau, China. Hydrology and Earth System Sciences, 16, 3199-3217. https://doi.org/10.5194/hess-16-3199-2012

[13] Matonse, A.H. and Kroll, C.N. (2013) Applying Hillslope-Storage Models to Improve Low Flow Estimates with Limited Streamflow Data at a Watershed Scale. Journal of Hydrology, 494, 20-31. https://doi.org/10.1016/j.jhydrol.2013.04.032 
[14] Khadka, D.B. (2019) Experimental Study of Runoff Coefficients for Different Hill Slope Soil Profiles. Open Journal of Civil Engineering, 9, 157-171.

[15] Instruction Manual (1995) Basic Hydrology System. S12 UK. 